\title{
"THIS ISN'T ME!": The Role of Age-Related Self- and User Images for Robot Acceptance by Elders
}

\author{
Melanie Dudek $^{1}\left[\right.$ Stefanie Baisch ${ }^{2} \cdot$ Monika Knopf $^{1} \cdot$ Thorsten Kolling $^{3}$
}

Accepted: 6 July 2020 / Published online: 27 October 2020

(c) The Author(s) 2020

\begin{abstract}
Although companion-type robots are already commercially available, little interest has been taken in identifying reasons for inter-individual differences in their acceptance. Elders' age-related perceptions of both their own self (self-image) and of the general older robot user (user image) could play a relevant role in this context. Since little is known to date about elders' companion-type robot user image, it is one aim of this study to investigate its age-related facets, concentrating on possibly stigmatizing perceptions of elder robot users. The study also addresses the association between elders' age-related self-image and robot acceptance: Is the association independent of the user image or not? To investigate these research questions, $N=28$ adults aged 63 years and older were introduced to the companion-type robot Pleo. Afterwards, several markers of robot acceptance were assessed. Actual and ideal self- and subjective robot user image were assessed by a study-specific semantic differential on the stereotype dimensions of warmth and competence. Results show that participants tended to stigmatize elder robot users. The self-images were not directly related to robot acceptance, but affected it in the context of the user image. A higher fit between self- and user image was associated with higher perceived usefulness, social acceptance, and intention to use the robot. To conclude, elders' subjective interpretations of new technologies play a relevant role for their acceptance. Together with elders' individual self-images, they need to be considered in both robot development and implementation. Future research should consider that associations between user characteristics and robot acceptance by elders can be complex and easily overlooked.
\end{abstract}

Keywords Companion-type robots · Self-Congruity Theory $\cdot$ Disengagement research $\cdot$ Assistive technology $\cdot$ Robot acceptance

Melanie Dudek

melanie.d@t-online.de

Stefanie Baisch

stefanie.baisch@uni-siegen.de

Monika Knopf

knopf@psych.uni-frankfurt.de

Thorsten Kolling

kolling@psychologie.uni-kiel.de

1 Developmental Psychology Lab, Goethe University of Frankfurt am Main, Frankfurt, Germany

2 Psychological Ageing Research, University of Siegen, Siegen, Germany

3 Developmental and Child and Adolescent Clinical Psychology Unit, Christian-Albrechts-University of Kiel, Kiel, Germany

\section{Introduction}

Due to ongoing technologization of our societies, elders are confronted already nowadays with a wide range of new technologies. In the recent decade, particular effort has been made to develop assistive robots for the elders, i.e., robots aimed at providing support with everyday challenges. Many of these robots are equipped with social and communicative abilities, and are hence called assistive social robots [8]. According to the authors, they can be further distinguished based on their functionality: Service-type robots, on the one hand, provide practical support, e.g., regarding activities of daily living, mobility, or safety. Companion-type robots, on the other hand, are intended primarily at supporting social and emotional needs.

Indeed, positive effects of companion-type robots on mood, feelings of loneliness, and well-being have been reported for elders suffering from dementia [39], but also 
for cognitively healthy elders [5]. Since these effects can only unfold when elders actually engage with the robots, acceptance by the target group is key to effectiveness (also see [29]). Current findings on the acceptance of companiontype robots are generally promising [26], but wide interindividual differences have also been reported [10, 25]. It is important to understand the reasons for these inter-individual differences as this knowledge can promote user-centered robot development and can help to better understand the individual elder's reaction towards companion-type robots.

In this article, we propose that inter-individual differences in elders' age-related perceptions of themselves and their environment play a relevant role regarding companion-type robot acceptance. We suggest that two age-related perceptions are of particular interest in this context: Firstly, elders' age-related self-images, i.e., elders' age-related perceptions of their own person, could affect robot acceptance, since the individual self-image is known to affect behavior [2, 13, 52]. Secondly, elders' age-related user image, i.e., their age-related perceptions of the general older companion-type robot user, could also play a relevant role in this context: A user image stereotyping the person using the robot could put elders off and reduce robot acceptance.

As little is known on elders' user image of companion type robots, we firstly investigate the age-related robot user image using the companion-type robot dinosaur Pleo as example. Secondly, we assess possible associations between age-related self- and user images, and, finally we concentrate on how the age-related self- and user images are associated with robot acceptance.

\subsection{Companion-Type Robots: Human-Robot Interaction and Robot Acceptance}

Companion-type robots are designed to mimic living beings by appearance and function. Mostly, they resemble animals, i.e., they can usually move their head, limbs, and tail, and some of them can walk. They also utter noises and react to voice and touch. A pre-programmed personality, mood states, the need for "food", and the occasional "illness" are optional features implemented in some robots, and are intended at further increasing the impression of a real animal with its proper feelings and needs [e.g. 9, 15, 31].

Companion-type robots can show both proactive and reactive behavior. As reactive behavior, for example, they reward a user's nurturing behavior by positive reactions such as snuggling and cooing [9]. They can also show distress (uncomforting sounds or turning away) as a reaction to maltreatment [48]. In contrast, proactive behavior is random and not related to the user's actions. On the one hand, this is intended at fostering the impression of a real animal with its own will and temper, and, on the other hand, this is assumed to (re)orient the user's attention towards the robot [50].
Since it is the main aim of companion-type robots to provide positive, meaningful interactions between the robot and the human user, they are designed to appear most appealing. In particular, a disproportionately big head, big wide eyes, and a small nose elicit the impression of a cute, unthreatening little baby-animal [35]. This promotes the biological drive to support and protect a helpless creature (see [20, 23, 49]).

According to [28], it is this biological drive which prompts the user to take up interaction with the companiontype robot, attracted by the appealing baby-animal design. In this biologically-driven relationship-initiation phase the formation of a relationship with the companion-type robot is assumed to take place rather instantaneously at the start of the first human-robot interaction. In the subsequent behavior-dependent relationship maintenance phase, the rewarding nature of the interaction with the robot and its animal-like characteristics sustain an enduring human-robot relationship. Thus, for the initial formation of a human-robot relationship, the user's attraction to the robot is key.

However, "beauty lies in the eye of the beholder" (Thukydides, greek historican, 454b.c.-ca. 397b.c.) and humans usually don't adhere mindlessly to biological drives. Rather, individual lifetime experiences, values, and cultural norms can override these drives and affect human behavior and attitudes. Consequentially, it can be assumed that these aspects also play a relevant role for initial acceptance of a companion-type robot in the relationship initiation phase. Since negative ageing stereotypes are still prevalent in our societies and affect not only how others perceive elders, but also how elders perceive themselves, elders' age-related selfimages may plays a particularly relevant role in this context.

\subsection{The Self-Image in the Context of Robot Acceptance}

The self-image, also called self-concept, is defined as the perceptions of a person regarding his or her own self, including thoughts, feelings, and knowledge about the own identity [34]. According to [52], it is a multidimensional concept with four aspects: the actual self-image (perceptions about a person's current, private self), the ideal self-image (perceptions about the aspired self), the social self-image (assumed perceptions of others about the own self), and the ideal social self-image (aspired perceptions of others about the own self).

The age-related self-images can be affected by current ageing stereotypes as prevalent in the general population [30]. According to one of the most influential models on stereotyping, the Stereotype Content Model [16], elders are generally perceived as high in the domain of warmth (e.g., good-natured, friendly), but low in the domain of competence (e.g., dependent, unable). Since these ageing 
stereotypes can become integrated into the individual selfimages, they can become relevant in guiding elders' actions. For example, it has been shown that more negative agerelated self-images can be associated with disengagement, i.e., less preventive health behaviors [32], and less stimulating activities as well as a less active social life [37, 47]. Transferred to the topic of companion-type robots, this leads to the assumption that more negative age-related self-images could be associated with higher rejection of a companiontype robot.

\subsection{Self- and User Image in the Context of Robot Acceptance}

The assumption of a direct association between self-image and robot acceptance is supported by some consumer research studies (e.g., [19]). However, this direct approach has also been criticized for being too superficial [21]. Instead, it has been suggested that the self-image may exert its influence in the context of the user image.

\subsubsection{The User Image}

The term user image (product image in consumer research) denotes the characteristics attributed to the generalized user of a product [52]. Current literature suggests that companion-type robots could have a rather negative user image. It has been shown that elders associate the users of socially assistive robots with being old, lonely, dependent, and suffering from dementia [25, 40, 64]. Companion-type robots could be associated particularly strongly with negative ageing stereotypes, since their cute outer appearance and animal-mimicking functions could evoke the perception of a childish toy associated with infantilization of its user [28]. However, due to the qualitative nature of the available studies and limited sample sizes, knowledge on the user image of companion-type robots is still very limited.

Moreover, little is known on how elders come to hold a particular user image of companion-type robot users. However, it has been shown that user images can be constructed and altered in order to maintain a positive self-image [1, 62]. For example, elders apply negative age-related stereotypes for downward comparison [45], i.e., the negative evaluation of a group providing for a more positive self-evaluation [63]. Within these lines, elders were found to reject an assistive robot due to a subjective lack of need, independent of their objective level of functioning, putting forward that the assistive device has been developed for more impaired people than themselves [64]. This finding suggests that elders could construct the robot user image deliberately more negative than their individual self-image in order to maintain a positive self-image.

\subsubsection{The Role of Self- and User Image for Robot Acceptance}

Not only do elders use downward comparison to maintain a positive sense of self, they are also found to actively avoid the association with their age group in the presence of stimuli negatively related to age [61] in order to protect their self-image and self-esteem [60]. In line with this finding, Self-Congruity Theory [52] proposes that a better congruity, i.e., fit, between the subjective robot user image and an individual's self-image should be associated with higher robot acceptance, due to the human tendency to either maintain the actual self-image or to improve it towards the ideal selfimage. According to [52], the valence of the difference (i.e., whether the self- or the user image is more positive) is of no importance in this context.

Many of todays' elders perceive themselves more positively than current general ageing stereotypes [51] and are motivated to maintain positive age-related self-images [27]. By contrast, companion-type robots are likely to be attributed a negative, stereotyping age-related user image. Therefore, low congruity between the self-image and the user image could be associated with lower robot acceptance. This assumption is also supported by current literature on assistive device use by elders [24, 36, 42].

\subsection{The Concept of Robot Acceptance: Cognitive and Social Acceptance}

As has been outlined above, the social facets of robot acceptance, i.e., attachment and companionship, may play a particularly relevant role in the context of companion-type robots-more than for other types of assistive robots-, since their effects depend on the user building a relationship with the robot (also see [29]).

It has been shown before that people are indeed able to built a relationship with a robot (e.g., $[11,18,58])$. Nonetheless, the cognitive facet of robot acceptance, namely the intention to use the robot, its perceived usefulness and its perceived ease of use [22], are the most widely used measures of robot acceptance, whilst companionship and attachment are only rarely ever assessed. In order to overcome this drawback, the current study assesses both cognitive and social robot acceptance.

\section{Method}

\subsection{Aims of this Study}

To date, little is known about how elders' individual agerelated perceptions of themselves and of companion-type robots affect robot acceptance in this target group. The 
Table 1 Demographic data, independence, life satisfaction, technical experience and social integration of the participants

\begin{tabular}{|c|c|c|c|c|c|}
\hline & $\mathrm{n}$ & $\%$ & M & SD & Range \\
\hline Gender (male) & 18 & 64.0 & & & \\
\hline Schooling (Abitur ${ }^{\mathrm{a}}$ : yes) & 19 & 68.0 & & & \\
\hline \multicolumn{6}{|l|}{ Relationship status } \\
\hline In a relationship/married & 23 & 79.0 & & & \\
\hline Single & 5 & 21.0 & & & \\
\hline Children (Yes) & 21 & 71.0 & & & \\
\hline Age (years) & & & 71.00 & 4.85 & $63-83$ \\
\hline Overall independence (scale range: $0-10)^{\mathrm{b}}$ & & & 9.41 & .99 & $7-10$ \\
\hline Overall life satisfaction (scale range: $0-10$ ) & & & 8.18 & 1.33 & $5-10$ \\
\hline Technical experience (scale range: $0-35$ ) & & & 26.50 & 7.51 & $10-35$ \\
\hline Close social contacts (number) & & & 12.21 & 15.41 & \\
\hline
\end{tabular}

$N=28 .{ }^{\text {a}}$ Equals A-levels

${ }^{\mathrm{b}}$ Data of one participant had to be excluded due to individual difficulties with this question self-image could play a relevant role in this context, but it remains yet unclear whether the relationship between self- and user image or the user image by itself affect robot acceptance, particularly cognitive and social acceptance of companion-type robots.

1. Since little is known on the user image of companiontype robots to date, the current study firstly investigates the age-related user image of this type of robot, using the companion-type robot Pleo.

2. Current research suggests that the user image is constructed in the context of the self-image. In order to examine this assumption we investigate

a. if self- and user image are related.

b. if the self-image is more positive than the user image, as suggested by current literature.

Moreover, we investigate the association between the self-image and robot acceptance by examining the following two mutually exclusive hypotheses:

3. a. More negative self-images are directly associated with lower robot acceptance (disengagement research), or

b. higher congruity between self- and user images is associated with higher robot acceptance (Self-Congruity Theory).

\subsection{Robot}

In this study, the commercially available companion-type robot Pleo (Innvo Labs ${ }^{\circledR}$ ), which is shaped like a dinosaur, was used. Like all companion-type robots, Pleo has builtin microphones, a camera, tilt and touch sensors, and can move limbs, head, and tail. Furthermore, a pre-programmed personality is implemented in this robot. In addition, the robot is also able to show different mood states depending on the user's behavior towards the robot. Moreover, Pleo can walk and has a sleep-wake-cycle. For a more detailed description of the robot's features and functions, see [15].

\subsection{Participants}

A random sample of $N=31$ participants was recruited from the University for the Elderly (U3L, Universität des Dritten Lebensalters) located at the Goethe University of Frankfurt am Main, Germany. Elders were eligible for participation if older than 60 years of age and of good subjective physical and cognitive health. ${ }^{1}$ Data of three participants had to be excluded, either due to difficulties filling in the questionnaires or due to technical problems during the human-robot interaction. Thus, the sample consisted of $N=28$ participants.

Sample details are presented in Table 1. All participants were Caucasian, and most of them were male and had taken the Abitur (German A-levels). None of the participants had met or learned about Pleo before. Note that, due to the fact that bad physical und cognitive health was an exclusion criterium, all participants showed rather high subjective independence (range: 7-10, scale range: 0-10; assessed by a single item, "All in all, how would you currently assess your own independence? This means your ability to perform the activities of daily life independently.").

\footnotetext{
1 The study was conducted in line with the ethical standards of the American Psychological Association and the German Association of Psychology (Deutsche Gesellschaft für Psychologie e.V., DGPs). Informed consent (written and verbal) was obtained from all participants.
} 


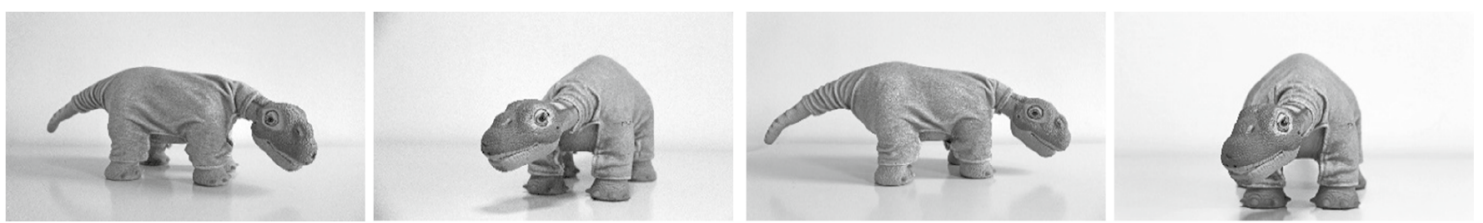

Fig. 1 Companion-type robot dinosaur Pleo

\subsection{Procedure and Design}

This study relies on a correlational design; all data was assessed by questionnaires. In order to introduce participants to the robot Pleo, an introduction procedure consisting of two parts was conducted with each participant in individual sessions.

Since today many people are not familiar with what companion-type robots can do, the first part was aimed at providing participants with information about Pleo's features and functions. To this end, a text was read out to the participants while showing them a slide show of the robot on a laptop (see Fig. 1).

In order to avoid biasing participants' perceptions of the robot and its user, care was taken to introduce Pleo as both an attractive gadget for younger people and as a therapeutic tool for elders with dementia. In previous studies we had gained the experience that media exposure biased some elder participants towards assuming that the robot is only used with people with dementia, whilst other participants, who had mostly not heard of companion-type robots in the media, assumed that it was a "cool gadget". When presenting the robot, the interviewer was not aware of the individual participants mind-set and therefore could introduce a bias by choosing a discrepant way of presenting the robot. Consequentially, the introduction session pointed out both mind-sets in order to establish a common frame of reference amongst participants in this study.

The second part of the introduction procedure provided opportunity for human-robot interaction. The respective participant was seated at a large table in order to ensure that he/ she had enough room to interact freely with the robot. Next, Pleo was presented and the participant was instructed that he/she could interact with the robot as he/she pleased. As a matter of caution, the participant was also told not to break the robot by letting it drop or by lifting it by its neck or tail. Then the interviewer left the room to prevent the participant from engaging in an interaction with the interviewer instead of with Pleo, and to ensure that the participant could interact freely with the robot. The participant interacted with the robot for approx. six minutes $(M=5.83, S D=1.22)$, before the interviewer re-entered the room. In our previous studies, we had made the experience that most participants had explored Pleo and its capabilities by this time and had formed a first impression of it. Finally, the participant was asked about his/her impression of the robot and the answers were noted in keywords (not part of the current article). Then the participant answered the questionnaires about his/ her acceptance and the user image of Pleo.

Demographic data and the different self-images were assessed prior to the introduction procedure. Questionnaires on the actual self-image were mailed to participants and filled in already at home, whereas the ideal and the ideal social self-images were assessed at the lab. The timely delay between the two assessments was intended at avoiding interferences between actual and ideal aspects of the self-image.

\subsection{Instruments}

\subsubsection{Intention to Use and Functional Robot Acceptance}

Functional robot acceptance was measured by two constructs, perceived ease of use and perceived usefulness. All of the constructs were measured on a 5-point Likert scale (I agree... I= not at all/5= completely) by items by [22] which were adapted to the affordances of the study. Two items of the ease of use scale were omitted, as they were not applicable to the current study ("I think I can use the robot dinosaur when there is someone around to help me./I think I can use the robot dinosaur when I have a good manual.").

\subsubsection{Social Robot Acceptance}

Social robot acceptance was measured by the Emotional Attachment Scale (EA-Scale) developed by [57] and the Comfort from Companion Animals Scale (CCAS) developed by [65]. One of the items of the EA-Scale was omitted due to overlap with an item of the CCAS ("The robot dinosaur makes me feel loved."). Furthermore, one CCAS item had to be omitted because most participants voiced difficulties understanding the item ("The robot dinosaur is a source of constancy in my life.").

A principal component analysis (Varimax-rotation with Kaiser-Criterion) was performed for each of the scales. EA-Scale showed a one-factorial solution with factor loadings $\lambda>.75\left(R^{2}=74 \%\right)$. Internal consistency was found to be very high (Conbach's $\alpha=.96)$. The mean score was used for analysis. For the CCAS, two factors were identified (see 
Table 2 Items of the Comfort from Companion Animals Scale (CCAS)

\begin{tabular}{lll}
\hline & Nurturing behavior & Fun and reassurance \\
\hline 11. The robot dinosaur makes me feel trusted & $\mathbf{. 7 8}$ & \\
10. The robot dinosaur makes me feel loved & $\mathbf{. 7 7}$ & \\
5. The robot dinosaur makes me feel needed & $\mathbf{. 8 7}$ & \\
2. Having a robot dinosaur gives me something to care for & $\mathbf{. 8 0}$ & .52 \\
1. The robot dinosaur provides me with companionship & $\mathbf{. 7 6}$ & .59 \\
7. Having a robot dinosaur gives me something to love & $\mathbf{. 6 6}$ & $\mathbf{. 8 7}$ \\
9. I enjoy watching the robot dinosaur & & $\mathbf{. 8 8}$ \\
6. The robot dinosaur makes me laugh and play & &. $\mathbf{7 1}$ \\
3. The robot dinosaur provides me with pleasurable activity & & $\mathbf{. 5 7}$ \\
8. I get comfort by touching the robot dinosaur & & \\
\hline
\end{tabular}

Principal Component Analysis, Varimax-rotation with Kaiser Criterion $\left(R^{2}=75 \%\right)$

Factor loadings assigned to scale are in boldface
Table 2). Both showed high to very high internal consistency (nurturing behavior: Conbach's $\alpha=.94$; fun and reassurance: Conbach's $\alpha=.86$ ). The mean score of each scale was computed, and the mean of these scale scores was used for analysis.

\subsubsection{Self-Image and User Image}

The user image was measured by a study-specific sevenpoint semantic differential consisting of 11 bipolar items (see Table 3). The scale was developed previously in an online study on the user image of companion-type robots in younger and older adults (see [Dudek 2017, unpublished manuscript], [3]). In this study, two of the original 13 items were omitted, because principal component analysis showed that they loaded poorly onto the factors in the current sample. The analysis yielded two factors, "warmth" and "competence", in line with the Stereotype Content Model by Fiske et al. [16]. The individual scales and the overall questionnaire showed high to very high internal consistency (overall: Conbach's $\alpha=.93$; warmth and competence, respectively: Conbach's $\alpha=.89$ ). The scale means as well as the overall mean, computed as the mean of the individual scales, was used for analysis.

The computation of self- and user image congruity requires self- and user image to rely on the same items. Consequentially, the items of the self-image questionnaires were identical with the user image items, with the instructions being adapted respectively. In this study, the actual, the ideal, and the ideal social self-image were assessed.

\subsubsection{Self-Image/User Image Congruity}

Although self-/user image congruity has been computed in many different ways $[7,54]$, the Generalized AbsoluteDifference Model showed to be the best mathematical model in this context [53]. It is computed as the absolute value of the summed differences between the self-image scores and the user image scores, divided by the number of items considered [53]:

$C_{k}=\left(\sum_{i=1}^{m}\left|U I_{i k}-S I_{i k}\right|\right) / n$

with $\mathrm{C}_{\mathrm{k}}=$ congruity score for participant $(\mathrm{k})$; $\mathrm{n}=$ number of items (i); $\mathrm{UI}_{\mathrm{ik}}=$ user image score of item (i) of participant $(\mathrm{k}) ; \mathrm{SI}_{\mathrm{ik}}=$ self-image score of item (i) of participant (k).

This means that higher scores of $\mathrm{C}_{\mathrm{k}}$ denote lower congruity, which is counter-intuitive. In order to facilitate intuitive understanding, we inverted $C_{k}$ with $C_{k-i n v}=-C_{k}$. As a consequence, in this paper, higher scores of $C_{k}$ denote higher congruity.

Table 3 Items (translated from German) of the self- and user image questionnaire and user image factor loadings after principal component analysis

\begin{tabular}{llc}
\hline & Competence & Warmth \\
\hline 1. Powerless-powerful & $\mathbf{. 7 4}$ & .55 \\
2. Conservative-modern & $\mathbf{. 8 1}$ & -.12 \\
3. Passive-active & $\mathbf{. 7 4}$ & .37 \\
4. Suffering from dementia-cognitively fit & $\mathbf{. 7 2}$ & .45 \\
5. Dependent-independent & $\mathbf{. 7 1}$ & .47 \\
6. Cold-warm & .07 & $\mathbf{. 8 6}$ \\
7. Insensitive-sensitive & .11 & $\mathbf{. 7 5}$ \\
8. Unfriendly-friendly & .45 & $\mathbf{. 7 8}$ \\
9. Socially isolated-socially integrated & .42 & $\mathbf{. 7 0}$ \\
10. Little interested in communication- & .56 & $\mathbf{. 6 7}$ \\
communicative & & \\
11. Egocentric-empathetic & .51 & $\mathbf{. 6 6}$ \\
\hline
\end{tabular}

Principal Component Analysis, Varimax-rotation with Kaiser Criterion $\left(R^{2}=71.46 \%\right)$

Factor loadings assigned to scale are in boldface 


\subsubsection{Technology Experience}

For additional analyses, general technology experience was assessed using the sum score of a 7-item questionnaire used in prior research (e.g., "A job that had a lot to do with technology, wouldn't have been for me.", $1=$ does not apply at all/5 = applies perfectly; [38]). Factor analysis showed a one-factorial solution; internal consistency was very high (Cronbach's $\alpha=.92$ ).

\subsection{Data Analysis}

Data analysis was performed using IBM SPSS statistics, version 20.

Within-group comparisons were performed using dependent t-Test for simple comparisons and repeated measures ANOVA for multiple comparisons. Since sphericity could not be assumed, the Greenhouse-Geisser correction was applied and multivariate tests are reported.

Between-group comparisons between normally distributed data were performed using independent $t$-Tests. Mann-Whitney-U-Tests were used for non-parametric comparisons.

Correlations between normally distributed data were computed as Spearman Correlation Coefficients, whilst Spearman Rank Order Correlations were used for nonparametric comparisons. The significance of the difference between correlation coefficients was assessed using Steiger's z-Test.

The significance level was generally set at $\alpha=.05$ for twosided tests and at $\alpha=.025$ for one-sided tests. For multiple tests, Bonferroni-correction was applied.

\section{Results}

\subsection{Preliminary Analysis: Discriminability of Actual, Ideal and Ideal Social Self-Image}

As previous research has found that people have difficulties discriminating between the social and the actual/ideal selfimage, we first investigated the discriminability of these two constructs.

Repeated measures ANOVA shows that the overall scores of the three self-images differed significantly from each other, $F=(2,26)=4.34, p=.024, \eta_{\mathrm{p}}{ }^{2}=.25$. Pairwise comparisons indicate that this was caused by significant differences between the actual $(M=5.85, S D=.53)$ and ideal selfimage $(M=6.19, S D=.45)$, diff $f_{\text {ideal-actual }}=.34, p=.017,95 \%$ $C I[.05, .64]$. No significant differences were found between the ideal social self-image $(M=6.12, S D=.51)$ and the ideal self-image $\left(\right.$ diff $\left._{\text {ideal-ideal social }}=.08, n s, 95 \% C I[-.13, .29]\right)$ or the actual self-image (diff ideal social-actual $=.27, n s, 95 \% C I$ $[-.03, .56])$.

As participants obviously had difficulties discriminating the ideal social self-image from the other self-images, the scale was discarded from further analysis.

\subsection{Pleo User Image}

As can be seen in Fig. 2, the overall user image was found to be slightly positive. $(M=4.40, S D=1.12)$. Analysis of the subscales reveals that the robot user is perceived as slightly higher in warmth $(M=4.55, S D=1.12)$ than in competence $(M=4.22, S D=1.27)$.

Mean values of the individual items of the user image as presented in Fig. 3 show that both negative and positive evaluations of the elder robot user can be found on both the warmth and the competence scales. On average, participants perceived the general robot user as particularly negative regarding a lack of social contact. Particularly positive were perceptions of the robot users as modern and cognitively healthy, as well as warm, sensitive, friendly, and empathetic.

A look at the standard deviation of each of the items (see Fig. 3) shows that the variance in the individual item scores was high $(.99<S D<1.83)$, indicating a high inter-individual variance in the Pleo user image.

\subsection{Relation between User Image and Self-Image}

\subsubsection{The User Image in Relation to the Self-Image}

Mauchly's test indicated that the assumption of sphericity had been violated, $\chi^{2}(2)=15.92, p<.01$. Therefore multivariate tests are reported $(\varepsilon=.69)$.

The results of the repeated measures ANOVA confirmed significant differences between the actual, ideal, and the user image, $F(2,26)=27.74, p<.01, \eta_{\mathrm{p}}^{2}=.68$. Follow-up contrasts comparing the actual and ideal self-image against the user image revealed, as expected, that both aspects of selfimage are evaluated significantly more positive than the user image (actual: $M=5.85, S D=.53 ; F(1,27)=41.07, p<.001$, $\eta_{\mathrm{p}}{ }^{2}=.60$; ideal: $M=6.19, S D=.45 ; F(1,27)=57.36$, $\left.p<.001, \eta_{\mathrm{p}}^{2}=.68\right)$.

T-Tests with Bonferroni correction $\left(\alpha_{\text {corr }}=.025 / 4=.006\right)$ were used to follow-up these findings for the two scales of warmth and competence. Regarding perceived warmth, both actual and ideal self-image $\left(M_{\text {actual }}=5.85, S D=.76\right.$; $\left.M_{\text {ideal }}=6.10, S D=.56\right)$ turned out to be significantly more positive than the user image $(M=4.55, S D=1.12)$, actual: $t(27)=-5.09, p<.001, r=.70$; ideal: $t(27)=-6.42$, $p<.001, r=.78$. With regard to perceived competence, again, both actual and ideal self-image $\left(M_{\text {actual }}=5.85\right.$, $S D=.51 ; M_{\text {ideal }}=6.31, S D=.49$ ) were found to be significantly more positive than the user image $(M=4.22$, 
Fig. 2 Mean values of the user image, actual self-image and ideal self-image overall and the scales warmth and competence. Error bars denote standard error

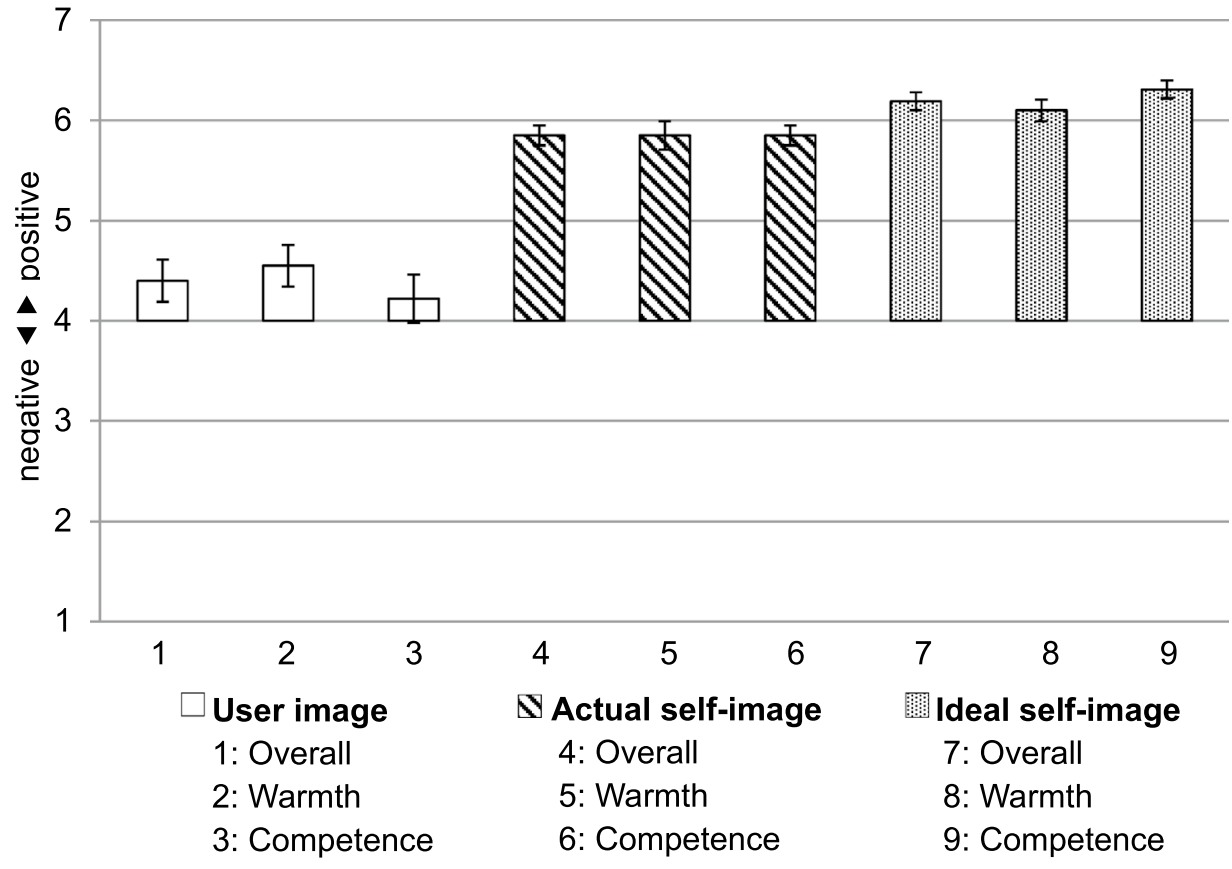

Fig. 3 Mean values of the individual items of the user image. Error bars denote standard deviation

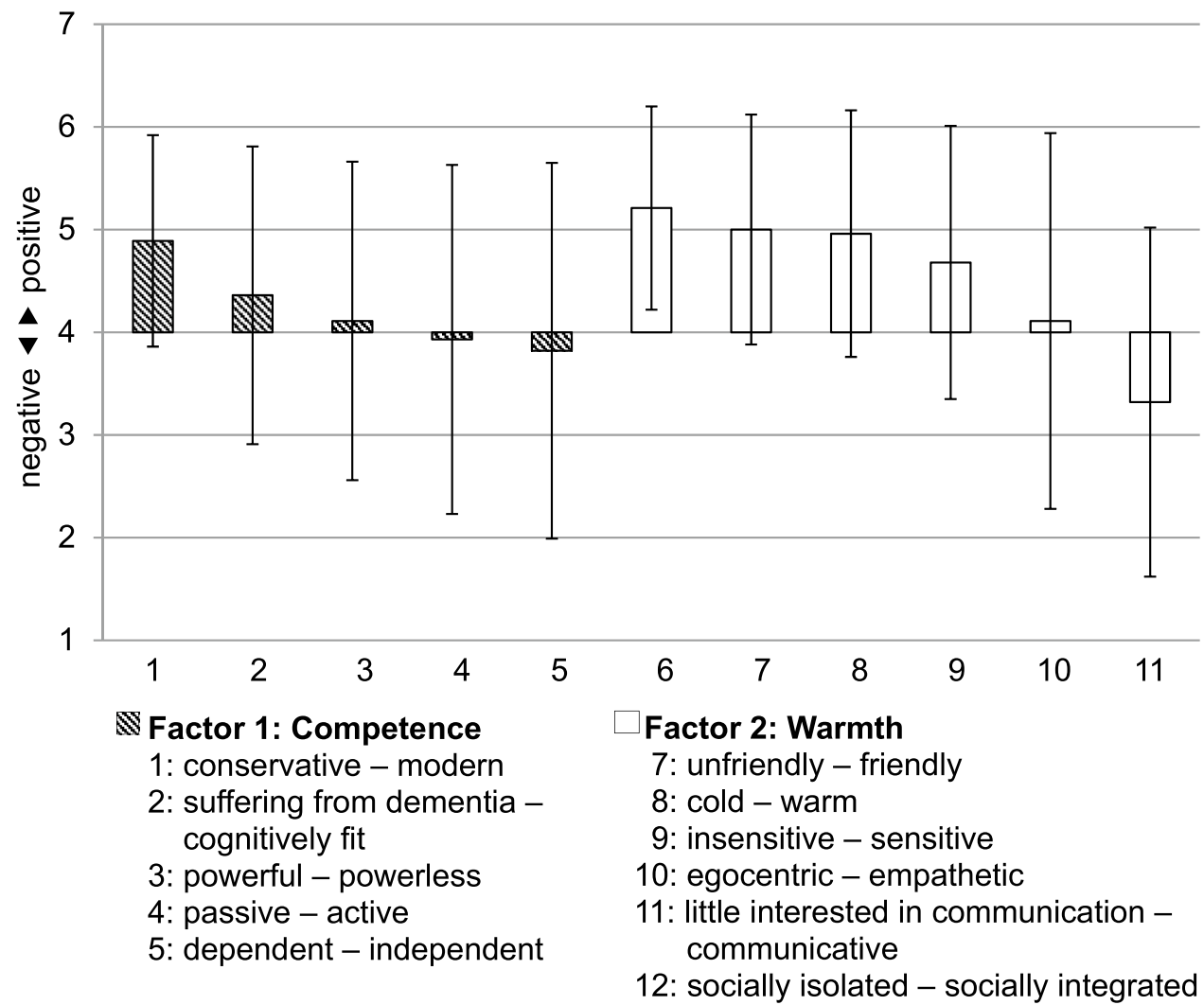

$S D=1.27)$, actual: $t(27)=-56.40, p<.001, r=.78$; ideal: $t(27)=-7.93, p<.001, r=.84$.

The assumption that the user image is generally more negative than the self-image, however, could not be confirmed. In this sample, $n=2$ participants $(7 \%)$ rated their actual self-images slightly more negative than the user image (scores: .15 and .58 , respectively; scale range: $10-7 \mid)$, and $n=2$ participants $(7 \%)$ rated their ideal self-image slightly more negative than the user image (scores: .27 and .12 , respectively; scale range: $|0-7|)$. Analysis of person-related characteristics 
Table 4 Association of self-image, user-image, and congruity with acceptance of Pleo

\begin{tabular}{|c|c|c|c|c|c|}
\hline & \multirow[t]{2}{*}{ Intention to use } & \multicolumn{2}{|c|}{ Functional acceptance } & \multicolumn{2}{|c|}{ Social-emotional acceptance } \\
\hline & & $\begin{array}{l}\text { Perceived } \\
\text { usefulness }\end{array}$ & $\begin{array}{l}\text { Perceived ease } \\
\text { of use }\end{array}$ & Attachment & Companionship \\
\hline Actual self-image (overall) & $n s$ & $n s$ & $.45^{* *}$ & $n s$ & $n s$ \\
\hline Ideal self-image (overall) & $n s$ & $n s$ & $n s$ & $n s$ & $n s$ \\
\hline Actual self-/user image congruity (overall) & $.57 * *$ & $n s$ & $n s$ & $.65^{* * * *}$ & $.54 * *$ \\
\hline Ideal self-/user image congruity (overall) & $.56 * *$ & $.32 *$ & $n s$ & $.69 * * *$ & $.69 * * *$ \\
\hline
\end{tabular}

Non-parametric Spearman's Rho Correlation Coefficients

${ }^{*} p<.05$.; ** $p<.01 ; * * * p<.001$

Bold: correlations remaining significant after correcting $\alpha=.025$ to $\alpha_{\text {corr }}=.025 / 20=.0013$ due to multiple testing

revealed that one of the three participants concerned in total was living alone, had no children, and showed comparably low life satisfaction. The second one was also living alone and had no children, and suffered from comparably low subjective independence. The third one was married, but also had no children, and stated to have no significant others apart from his wife.

\subsubsection{Association Between Self- and User-Image}

Mean overall and factor scores of user image, actual selfimage, and ideal self-image are shown in Fig. 2. Contrary to the initial expectation, no significant correlations of the user image with the actual $(r(28)=.09, n s)$ or ideal self-image $(r(28)=-.11, n s)$ were found.

\subsection{Association of Robot Acceptance with Self- and User Image}

\subsubsection{Association Between Self-Image and Robot Acceptance}

The results are presented in Table 4. After Bonferronicorrection for multiple testing $\left(\alpha_{\text {corr }}=.025 / 20=.0013\right)$, a statistical trend regarding an association between perceived ease of use and the actual self-image $\left(r_{s}(28)=.45\right.$, $p=.008$ ) was found. This was due to significant correlation between ease of use and the actual self-image regarding warmth $\left(r_{s}(28)=.49, p=.004\right)$ but not regarding competence $\left(r_{s}(28)=.23, n s\right)$. No other significant association between self-image and acceptance of Pleo was found.

\subsubsection{Association of Self- and User-Image Congruity with Robot Acceptance}

As can be seen in Table 4, perceived ease of use showed no significant correlation with self-/user image congruity.

After Bonferroni-correction for multiple testing $\left(\alpha_{\text {corr }}=.025 / 20=.0013\right)$, intention to use, attachment, and companionship correlated highly significantly with congruity for both the actual and the ideal self-image. Detailed analysis showed that with regard to the ideal self-/user image congruity, correlations with intention to use, attachment, and companionship were slightly higher for the factor of competence than of warmth (see Table 5). However, the correlation coefficients did not differ significantly (crit. value $=2.06 ; d f=25 ;|-.75|<|z|<|-.51|$ ). A trend for higher correlations according to one of the factors could not be observed with regard to the actual self-/ user image congruity ( see Table 5).

Finally, a trend for a correlation of ideal self-/user image congruity with perceived usefulness of the robot was found $\left(r_{s}(28)=.32, p=.048\right)$. This association was due to a slight trend for a correlation between perceived ease of use and the ideal self-image regarding competence $\left(r_{s}(28)=.31, p=.052\right)$, but not regarding warmth $\left(r_{s}(28)=.23, n s\right)$.

Table 5 Association of congruity scales competence and warmth with acceptance of Pleo

\begin{tabular}{llll}
\hline & Intention to use & \multicolumn{2}{l}{ Social-emotional acceptance } \\
\cline { 3 - 4 } & & Attachment & Companionship \\
\hline Actual self-/user & & \\
Competence & $.45^{*}$ & $.62^{* *}$ & $.47^{* *}$ \\
Warmth & $.51^{* *}$ & $.55^{* *}$ & $.47^{* *}$ \\
Ideal self-/user image congruity & & \\
Competence & $.55^{* *}$ & $.66^{* *}$ & $.66^{* *}$ \\
Warmth & $.49^{*}$ & $.59^{* *}$ & $.58^{* *}$ \\
\hline
\end{tabular}

Non-parametric Spearman's Rho Correlation Coefficient

$* p<.05$.; ** $p<.01$

Bold: Higher coefficients when comparing competence and warmth 


\subsection{Additional Analysis}

\subsubsection{Gender Differences}

With regard to the overall user image, male and female participants showed no significant differences (male: $M=4.42$, $S D=.98$; female: $M=4.36, S D=1.39 ; t(26)=.12, n s)$. With regard to robot acceptance, male and female participants showed no significant differences regarding their intention to use the robot (male: $M d n=1.50$; female: $M d n=1.17$; $z=-.70, n s$ ), its perceived usefulness (male: $M d n=1.00$; female: $M d n=1.00 ; z=-.08, n s$ ), and its perceived ease of use (male: $M d n=4.00$; female: $M d n=4.00 ; z=-.66, n s$ ). Furthermore, they did not differ regarding their attachment (male: $M d n=3.78$; female: $M d n=2.72 ; z=-.82, n s$ ), and companionship towards the robot (male: $M d n=1.96$; female: $M d n=2.16 ; z=-.17, n s)$.

\subsubsection{The Relevance of Technology Experience}

A trend towards an association between higher general technology experience and higher perceived ease of use was shown $\left(r_{s}(28)=.36, p=.057\right)$, but no other significant correlations with variables of robot acceptance were found $\left(.03<\left|r_{s}(28)\right|<.16, n s\right)$. Moreover, no significant association of technology experience and the user image was found $\left(r_{s}(28)=.18, n s\right)$.

\section{General Discussion}

The current study investigates the role of two specific domains of age-related perceptions for the acceptance of companion-type robots, i.e., the individual age-related selfimage and the age-related user image, using the robot dinosaur Pleo as example. It was examined whether the selfimage was directly associated with robot acceptance, as predicted by disengagement research, or if it affected robot acceptance in the context of the user image, as predicted by Self-Congruity Theory [52]. Moreover, the structure of elders' age-related robot user image was also investigated.

\subsection{How is the Elder User of a Companion-Type Robot Perceived by Elders?}

\subsubsection{User Image in Relation to the Self-Image}

Corroborating current research findings [25, 40, 65], the current study shows that, on average, participants perceive the general companion-type robot user more negative than themselves. Only three participants rated the robot user image more positive than their own self-image. They were found to suffer from particularly pronounced impairments in independence, psychological, or social functioning as compared to the majority of sample. Since participants in this study were rather healthy and active, it can be suggested that, in a more diverse sample, a higher percentage of participants might rate the user image more positive than their own self-image.

It has to be noted further that the variance in the user image was quite large in this sample, indicating that this is a highly subjective construct. According to Pape et al. [42], acceptance of disability, i.e., fear of future disability, personal values, and health-related coping can influence the meaning ascribed to assistive devices. Consequentially, future studies should investigate to which extend elders' individual characteristics affect their perceptions of the robot user.

According to the findings of this study, it is not the selfimage which affects the user image as no significant association between self- and user image was found. Contrary to what was suggested by previous findings [42, 64], this speaks against the construction of the user image in relation to the self-image. As one possible explanation, most participants may have recognized the robot as an assistive device, deducing therefrom that impaired elders might be the appropriate user group and describing the general user accordingly. Hence, the cognitively and physically healthy, active participants might have constructed a user image naturally more negative than their own.

\subsubsection{Stereotypization of Robot Users}

In accordance with general ageing stereotypes [16], the general Pleo user was perceived as high in warmth, but comparably low in competence. In particular, the general robot user was perceived as socially isolated, a finding in line with the current literature $[25,40]$. A real robot user eliciting negative ageing stereotypes in others may experience negative social consequences, e.g., social isolation or age-inappropriate treatment. In order to avoid stigma by robot use in public, more research is needed investigating the stigma associated with public robot use by elders and the factors affecting agerelated user perceptions.

However, it also needs to be pointed out that the general Pleo user was also perceived as rather modern and cognitively healthy, probably because he/she is engaging with modern technology. Such positive aspects of the user image can counteract stigma and should thus be pronounced more strongly by the robot's design.

\subsection{Association of Robot Acceptance with the Self-Image and the Role of the User Image}

With regard to the relationship between the age-related selfimages and robot acceptance, the only significant association was shown between higher perceived ease of use and a more 
positive actual and ideal self-image. The association was particularly pronounced in the domain of warmth. Possibly participants perceiving themselves as warm and aspiring to be warm felt more confident to attend to the "needs" of the robot dinosaur. However, a general pattern of direct associations between the self-images and robot acceptance was not observed.

Instead, the findings largely support the assumptions of Self-Congruity Theory for the acceptance of companiontype robots by elders. Higher actual self and ideal self-/user image congruity was associated with higher intention to use the robot and higher social robot acceptance. This suggests that participants identifying more with their subjective robot user image were not only more likely to use it, but also felt less embarrassed to emotionally commit to it.

Whereas self- and user image congruity are significantly associated with intention to use and social aspects of robot acceptance, it is hardly associated with functional robot acceptance. Instead, higher ease of use was related to higher technology experience, suggesting that participants perceive the robot as a technological artifact, not as living being. This is intriguing, considering that a more positive self-image in the domain of warmth, i.e., social qualities necessary when in touch with living beings, is also associated with higher ease of use, suggesting that the robot is perceived as livelike. Prior research suggests that people use mental schemas of previous experience (i.e., technology/living beings) based on their first impression of the robot (e.g. [4, 14, 43, 44, 56]). Hence, the results suggest that Pleo was identified as having aspects of both robot and living being. This reinforces the assumption that mental schemas about the robot and its user can affect robot acceptance in complex ways.

In addition, higher congruity between the ideal self-image and the robot user image was associated, although not significantly, with higher perceived usefulness of the robot. Since the relationships between variables of acceptance and ideal self-image were somewhat more pronounced in the domain of competence than in the domain of warmth, it can be assumed that participants considered the robot as a useful mean of self-enhancement, perceiving the robot user to have age-related competences they themselves want to achieve.

Taken together, these findings show that elders' identification with the robot user group, not only with regard to their current, but also with regard to their aspired self-image is important for robot acceptance by elders.

\subsection{Limitations of the Study}

It has to be noted that most participants in this study were Caucasian and highly educated. It has been shown that culture affects robot preference on a number of dimensions of robot design [33]. Hence, cross-cultural studies are necessary to determine the robot user image in different cultures or nationalities. Moreover, participants were rather high functioning, in line with their very positive self-images. As a consequence, the number of elders holding a selfimage more negative than their robot user image may have been underestimated as compared to the general population. However, since the study by $\mathrm{Wu}$ et al. [64] suggests that elders tend to hold a rather positive self-image regardless of their objective abilities, no definite conclusion in this regard can be drawn. More diverse samples, including more impaired elders, are needed to extend the current results.

Moreover, in this study, only one companion-type robot was used as example. As it has been shown that product design can affect the brand or product image [62], research involving a variety of robots is needed in order to investigate what exactly causes specific user images and to extend the current results to other classes of robots for elders.

Finally, attachment and companionship were measured after a single six-minutes interaction in the relationshipinitiation phase of human-robot interaction. Of course, it can be assumed that attachment and companionship change and develop in the following relationship-maintenance phase. Although long-term studies on changes in robot acceptance exist [12, 15], they mostly concentrate on cognitive aspects of robot acceptance, i.e., usefulness, ease of use, and intention to use. Further studies are needed to investigate the change in companionship and attachment towards the robot in the longer run.

\subsection{Study Implications}

Firstly, the current study shows that a negative robot user image might stigmatize elder robot users. Secondly, the study also shows that elders tend to reject a robot if its user image does not fit their individual self-image. This means that elders may not only evaluate the general robot user negatively, this negative evaluation can also affect their robot acceptance. The moderate to strong associations between self-/user image congruity and robot acceptance shows how relevant the topic is with regard to elders' robot acceptance. As a consequence, it seems that the biologically driven attraction to the robot in the relationship-initiation phase [28] can indeed be overridden by socially and culturally shaped attitudes and values, as can be expected. Yet, although a negative user image can counteract the biological drive to attend to the robot, a positive user image can also foster robot attraction. After all, the robot user is also perceived as modern and cognitively healthy.

These findings have important implications for both robot implementation and robot development. 


\subsubsection{Implications for Robot Implementation}

Although user images are shaped by presentations in the media, they are also shaped by social norms in the individual's vicinity. Therefore, possible group dynamics have to be kept in mind when introducing a robot to a group of elders for the first time: Chances are high that in a group introduction, the individual robot user image will converge towards the user image voiced most loudly or vehemently in the group. As a consequence, elders with low self-confidence may refrain from robot use if confronted with a negative group opinion. This means that particularly those elders who could benefit most from robot use would exclude themselves from this experience due to fear of stigmatization [3] showed, e.g., that elders with symptoms of depression are those who might be most reluctant to use a companion-type robot whilst at the same time being those probably most in need of it. Consequentially, private introduction sessions, addressing the elder person's individual user image in the context of his/her self-image, are to be preferred. These sessions are not primarily intended at impacting on the individual elder's user image - research is needed if and how the individual user image can be modified in the first place-, they are aimed at giving less self-confident elders the opportunity to positively experience the relationship-initiation phase with the robot without being demotivated by others. Moreover, elders should be given the opportunity to choose between group and private robot interaction opportunities in order to encourage less self-confident elders to interact with the robot beyond the first relationship-initiation phase. Privacy could allow them to build up a lasting relationship with the robot in the relationship-maintenance phase in private.

On more general grounds, self-images are shaped by cultural norms and general ageing stereotypes as present in our society [26, 55]. All the same, individual user images are also shaped by public opinion, which, in turn, is largely shaped by the media. Participants in this study seemed to recognize the robot as an assistive device for frail elders despite the fact that both scenarios, assistive device for people suffering from dementia and an interesting gadget for modern elders, were highlighted in the introduction session. This is most probably due to the presentation of companiontype robots in German media. Hence, researchers and robot producers need to be conscientious about how to introduce a robot to the general public, since emphasizing age-related losses could reduce robot acceptance in the target group.

\subsubsection{Implications for Robot Development and Future Research}

Of course, it would be preferable in the first place to offer companion-type robots with a positive user-image so that elders can more easily commit to the robot without fear of stigmatization. Robot development research can contribute to this end by designing robots highlighting positive aspects of the user image (i.e., a modern mind-set) by appearance and function, whilst avoiding the association with negative aspects of the user image (i.e., social isolation). Ethical design is one of the targets of the IEEE Onthological Standard for Ethically Driven Robotics and Automation Systems [41] which is currently developed. The requirement of a positive user image should be represented in the robotic ontological standard since it contributes to a more ethical, i.e., less stereotyping, design of companion-type robots.

Yet, although much research has been presented regarding the role of robot design for robot acceptance (e.g., [6, 33, 46, 59]), the user image has not received any attention. Therefore, research using a variety of robots is needed to identify which key features of appearance and functions elicit a certain user image. In this context, it could be particularly interesting to investigate how to balance robot design between biologically driven attraction and norm-based repulsion. It could become apparent that the overly cute robot design as currently preferred for companion-type robots is, in fact, counter-productive to their acceptance. Since user characteristics like culture, gender, or education can affect robot acceptance [17], future research should also investigate the effects of different user characteristics on the user image.

Moreover, since elders prefer a robot of which the user image is similar to their own age-related self-image, a matching design could largely improve robot acceptance. This calls for the development of a variety of companiontype robots differing by design or to an individually adaptive robot design. As a consequence, it is not only important to know which robot characteristics elicit a certain user image, but it is also mandatory for robot developers to attain a thorough knowledge of the respective target group.

\subsection{Conclusions}

Taken together, the current study shows that elders' interpretations of new technologies, i.e., robots, play a very relevant role with regard to their acceptance. Although negative reactions to companion-type robots and inter-individual differences in their acceptance have been reported [10, 12, 15], they are only rarely systematically addressed in current studies. Associated research domains, e.g., research on the non-use of assistive devices in general, have already proceeded further on this topic, presenting a body of research on reasons for use and non-use of assistive devices. The current study parallels these results in the domain of robot acceptance by showing that a subjective need is not the only factor affecting robot acceptance and use.

Moreover, the current study shows that the associations between user characteristics and robot acceptance can be complex and may thus be easily overlooked. This would 
largely impair our understanding of robot acceptance in the elder population. By using theories from social science to explain variance in robot acceptance, it shows that social sciences can contribute to developing ethical and acceptable robot design by investigating how elders perceive and assign meaning to new technologies, and by identifying factors influencing these judgments. This does not only enlarge our scientific understanding of elders' views on new technologies, but can also help to minimize stigma by design and to improve acceptance in the elder population.

Funding Open Access funding enabled and organized by Projekt DEAL.

\section{Compliance with Ethical Standards}

Conflict of interest The authors declare that they have no conflict of interest.

Human and Animal Rights The study was conducted in line with the ethical standards of the American Psychological Association and the German Association of Psychology (Deutsche Gesellschaft für Psychologie e.V., DGPs)

Informed Consent Informed consent was obtained from all participants.

Open Access This article is licensed under a Creative Commons Attribution 4.0 International License, which permits use, sharing, adaptation, distribution and reproduction in any medium or format, as long as you give appropriate credit to the original author(s) and the source, provide a link to the Creative Commons licence, and indicate if changes were made. The images or other third party material in this article are included in the article's Creative Commons licence, unless indicated otherwise in a credit line to the material. If material is not included in the article's Creative Commons licence and your intended use is not permitted by statutory regulation or exceeds the permitted use, you will need to obtain permission directly from the copyright holder. To view a copy of this licence, visit http://creativecommons.org/licenses/by/4.0/.

\section{References}

1. Armenta BM, Stroebe K, Scheibe S, Postmes T, Van Yperen NW (2017) Feeling younger and identifying with older adults: testing two routes to maintaining well-being in the face of age discrimination. PLoS ONE 12(11):e0187805. https://doi.org/10.1371/journ al.pone. 0187805

2. Ackard DM, Kearney Cooke A, Peterson CB (2000) Effect of body image and self-image on women's sexual behaviors. Int J Eat Disorder 28(4):422-429. https://doi.org/10.1002/1098108X(200012)28:4\%3C422::AID-EAT10\%3E3.0.CO;2-1

3. Baisch S, Dudek M, Kolling T, Knopf M (2017) Factors impacting on perceptions of elder robot users. In: Poster presented at the 21st IAGG World Congress, San Francisco

4. Baisch S, Kolling T, Klein B, Pantel J, Oswald F, Knopf M (2018) Dynamic interplay between general experience and robot-specific expertise at older adults 'first encounter with a robot: role for robot acceptance and implications for robot design. Gerontechnology 17(4):215-231. https://doi.org/10.4017/gt.2018.17.4.003.00

5. Banks MR, Willoughby LM, Banks WA (2008) Animal-assisted therapy and loneliness in nursing homes: use of robotic versus living dogs. J Am Med Dir Assoc 9(3):173-177. https://doi. org/10.1016/j.jamda.2007.11.007

6. Barnes J, FakhrHosseini M, Jeon M, Park CH, Howard A (2017) The influence of robot design on acceptance of social robots. In: 2017 14th international conference on ubiquitous robots and ambient intelligence (URAI), pp 51-55. https://doi.org/10.1109/ URAI.2017.7992883

7. Birdwell AE (1968) A study of the influence of image congruence on consumer choice. J Bus 41(1):76-88. https://doi. org/10.1086/295047

8. Broekens J, Heerink M, Rosendahl H (2009) Assistive social robots in elderly care: a review. Gerontechnology 8(2):94-103. https://doi.org/10.4017/gt.2009.08.02.002.00

9. Chang WL, Sabanović S, Huber L (2013) Situated analysis of interactions between cognitively impaired older adults and the therapeutic robot PARO. In: Herrmann G, Pearson MJ, Lenz A, Bremner P, Spiers A, Leonards U (eds) Social robotics. ICSR 2013. Springer, Cham, pp 371-380. https://doi.org/10.1007/9783-319-02675-6_37

10. De Graaf MMA, Allouch SB (2014) Evaluation of a socially assistive robot in eldercare. Workshop paper presented at the International Conference on Human-Robot Interaction, Bielefeld, Germany

11. De Graaf MMA, Allouch SB (2017) The influence of prior expectations of a robot's lifelikeness on users' intentions to treat a zoomorphic robot as a companion. Int J Soc Robot 9(1):17-32. https ://doi.org/10.1007/s12369-016-0340-4

12. De Graaf MMA, Allouch SB, Van Dijk JAGM (2016) Longterm evaluation of a social robot in real homes. Interact Stud 17(3):462-491. https://doi.org/10.1075/is.17.3.08deg

13. Dunning D (2007) Self-ghimage motives and consumer behavior: how sacrosanct self-beliefs sway preferences in the marketplace. J Consum Psychol 17(4):237-249. https://doi.org/10.1016/S1057 -7408(07)70033-5

14. Ezer N, Fisk AD, Rogers WA (2009) Attitudinal and intentional acceptance of domestic robots by younger and older adults. Univers Access Human Comput Interact 5615:39-48. https://doi. org/10.1007/978-3-642-02710-9_5

15. Fernaeus Y, Håkansson M, Jacobsson M, Ljungblad S (2010) How do you play with a robotic toy animal?: a long-term study of Pleo. In: Proceedings of the 9th international conference on interaction design and children. Barcelona, pp 39-48. https://doi. org/10.1145/1810543.1810549

16. Fiske ST, Cuddy AJ, Glick P, Xu J (2002) A model of (often mixed) stereotype content: competence and warmth respectively follow from perceived status and competition. J Pers Soc Psychol 82(6):878-902. https://doi.org/10.1037/0022-351482.6.878

17. Flandorfer P (2012) Population ageing and socially assistive robots for elderly persons: the importance of sociodemographic factors for user acceptance. Int J Popul Res. https://doi. org/10.1155/2012/829835

18. Fujita M (2004) On activating human communications with pet-type robot AIBO. Proc IEEE 92(11):1804-1813. https://doi. org/10.1109/JPROC.2004.835364

19. Gentry JW, Doering M (1977) Masculinity-femininity related to consumer choice. In: Greenberg BA, Bellenger DN (eds) Contemporary marketing thought, Proceedings of the American Marketing Association, vol. 41. Marketing classic press, Georgia, pp 423-427

20. Glocker ML, Langleben DD, Ruparel K, Loughead JW, Gur RC, Sachser N (2009) Baby schema in infant faces induces cuteness perception and motivation for caretaking in adults. Ethology 
115(3):257-263. https://doi.org/10.1111/j.1439-0310.2008.01603 .X

21. Grubb EL, Grathwohl HL (1967) Consumer self-concept, symbolism and market behavior: a theoretical approach. J Marketing 31(4):22-27. https://doi.org/10.2307/1249461

22. Heerink M, Kröse B, Evers V, Wielinga B (2010) Assessing acceptance of assistive social agent technology by older adults: the Almere Model. Int J Soc Robot 2(4):361-375. https://doi. org/10.1007/s12369-010-0068-5

23. Hinde RA, Barden LA (1985) The evolution of the teddy bear. Animal Behav 33(4):1371-1373. https://doi.org/10.1016/S0003 $-3472(85) 80205-0$

24. Hirsch T, Forlizzi J, Hyder E, Goetz J, Kurtz C, Stroback J (2000) The ELDer project: social, emotional, and environmental factors in the design of eldercare technologies. In: Proceedings on the 2000 Conference on Universal Usability. Arlington, pp 72-79. https://doi.org/10.1145/355460.355476

25. Hutson S, Lim SL, Bentley PJ, Bianchi-Berthouze N, Bowling A (2011) Investigating the suitability of social robots for the wellbeing of the elderly. In: D'Mello S, Graesser A, Schuller B, Martin JC (eds) Affective computing and intelligent interaction. Springer, Heidelberg, pp 578-587. https://doi.org/10.1007/9783-642-24600-5_61

26. Kidd CD, Taggart W, Turkle S (2006) A sociable robot to encourage social interaction among the elderly. In: Proceedings 2006 IEEE international conference on robotics and automation. Orlando, pp 3972-3976. https://doi.org/10.1109/ROBOT 2006.1642311

27. Kleinspehn-Ammerlahn A, Kotter-Grühn D, Smith J (2008) Selfperceptions of aging: do subjective age and satisfaction with aging change during old age? J Gerontol B Psychol 63(6):377-385. https ://doi.org/10.1093/geronb/63.6.P377

28. Kolling T, Baisch S, Schall A, Selic S, Rühl S, Kim Z et al (2016) What is emotional about emotional robotics? In: Tettegah SY, Garcia YE (eds) Emotions, technology, and health. Elsevier, Amsterdam, pp 85-103. https://doi.org/10.1016/B978-0-12-80173 7-1.00005-6

29. Kolling T, Haberstroh J, Kaspar R, Pantel J, Oswald F, Knopf M (2013) Evidence and deployment-based research into care for the elderly using emotional robots. J Gerontopsychol Geriatric Psych 26:83-88. https://doi.org/10.1024/1662-9647/a000084

30. Kornadt AE, Rothermund K (2011) Dimensionen und Deutungsmuster des Alterns. [Dimensions and interpretative patterns of ageing]. Z Gerontol Geriatr 44(5):291-298. https://doi. org/10.1007/s00391-011-0192-3

31. Kunimura H, Ono C, Hirai M, Muramoto M, Matsuzaki WT, Uchiyama T et al (2010) Baby robot "YOTARO". In: Yang HS, Malaka R, Hoshino J, Han JH (eds) Entertainment computing-ICEC 2010. Lecture Notes in Computer Science, vol 6243. Springer, Berlin, Heidelberg, pp 1-8. https://doi.org/10.1007/9783-642-15399-0_1

32. Levy BR, Myers LM (2004) Preventive health behaviors influenced by self-perceptions of aging. Prev Med 39(3):625-629. https://doi.org/10.1016/j.ypmed2004.02.029

33. Li D, Rau PP, Li Y (2010) A cross-cultural study: effect of robot appearance and task. Int J Soc Robot 2(2):175-186. https://doi. org/10.1007/s12369-010-0056-9

34. Liberatore A (2011) Psychologische Markenkommunikation: Selbstkongruenz zwischen Konsument und Marken. [Psychological brand communication: Self-congruence between consumer and brands]. BWV, Berlin

35. Lorenz K (1943) Die angeborenen Formen möglicher Erfahrung [The congenital forms of possible experience]. Zeitschrift für Tierpsychologie 5:235-409. https://doi. org/10.1111/j.1439-0310.1943.tb00655.x
36. McNeill A, Coventry L (2015) An appraisal-based approach to the stigma of walker-use. In: Zhou J, Salvendy G (eds) Human aspects of IT for the aged population-design for aging. Springer International Publishing, Swiss, pp 250-261. https://doi. org/10.1007/978-3-319-20892-3_25

37. Menkin JA, Robles TF, Gruenewald TL, Tanner EK, Seeman TE (2016) Positive expectations regarding aging linked to more new friends in later life. J Gerontol B Psychol 72(5):771-781. https:// doi.org/10.1093/geronb/gbv118

38. Mollenkopf H, Oswald F, Wahl H-W (2007) Neue PersonUmwelt-Konstellationen im Alter: Befunde und Perspektiven zu Wohnen, außerhäuslicher Mobilität und Technik [New personenvironment constellations in later life: findings and perspectives on housing, out-of-home mobility and technology]. In: Wahl H-W, Mollenkopf H (eds) Alternsforschung am Beginn des 21. Jahrhunderts. Alterns- und Lebenslaufkonzeptionen im deutschsprachigen Raum [Ageing research at the beginning of the 21st century]. Akademie-Verlag, Berlin, pp 361-380

39. Mordoch E, Osterreicher A, Guse L, Roger K, Thompson G (2013) Use of social commitment robots in the care of elderly people with dementia: a literature review. Maturitas 1:14-20. https://doi.org/10.1016/j.maturitas.2012.10.015

40. Neven L (2010) 'But obviously not for me': robots, laboratories and the defiant identity of elder test users. Sociol Health Illn 32(2):335-347. https://doi.org/10.111 $1 / \mathrm{j} .1467-9566.2009 .01218 . x$

41. Olszewska JI, Houghtaling M, Gonçalves P, Haidegger T, Fabiano N, Carbonera JL et al (2018) Robotic ontological standard development life cycle. In: EEE International Conference on Robotics and Automation (ICRA), pp 1-6

42. Pape TLB, Kim J, Weiner B (2002) The shaping of individual meanings assigned to assistive technology: a review of personal factors. Disabil Rehabil 24(1-3):5-20. https://doi. org/10.1080/09638280110066235

43. Parise S, Kiesler S, Sproull L, Waters K (1999) Cooperating with life-like interface agents. Comput Hum Behav 15(2):123-142. https://doi.org/10.1016/S0747-5632(98)00035-1

44. Pino M, Boulay M, Jouen F, Rigaud AS (2015) "Are we ready for robots that care for us?" Attitudes and opinions of older adults toward socially assistive robots. Front Aging Neurosci 7:141. https ://doi.org/10.3389/fnagi.2015.00141

45. Pinquart M (2002) Good news about the effects of bad oldage stereotypes. Exp Aging Res 28(3):317-336. https://doi. org/10.1080/03610730290080353

46. Prakash A, Rogers WA (2015) Why some humanoid faces are perceived more positively than others: effects of human-likeness and task. Int J Soc Robot 7(2):309-331. https://doi.org/10.1007/ s12369-014-0269-4

47. Robertson DA, Kenny RA (2016) "I'm too old for that"- the association between negative perceptions of aging and disengagement in later life. Pers Indiv Differ 100:114-119. https://doi. org/10.1016/j.paid.2016.03.096

48. Rosenthal-von der Pütten AM, Krämer NC, Hoffmann L, Sobieraj S, Eimler SC (2013) An experimental study on emotional reactions towards a robot. Int J Soc Robot 5(1):17-34. https://doi. org/10.1007/s12369-012-0173-8

49. Rosenthal-von der Pütten AM, Krämer NC (2014) How design characteristics of robots determine evaluation and uncanny valley related responses. Comput Human Behav 36:422-439. https://doi. org/10.1016/j.chb.2014.03.066

50. Salem M, Eyssel F, Rohlfing K, Kopp S, Joublin F (2011) Effects of gesture on the perception of psychological anthropomorphism: a case study with a humanoid robot. In: Mutlu B, Bartneck C, Ham J, Evers V, Kanda T (eds) Social Robotics. ICSR 2011. Lecture Notes in Computer Science, vol 7072. Springer, Berlin, 
Heidelberg, pp 31-41. https://doi.org/10.1007/978-3-642-25504 $-5 \_4$

51. Schiffman LG, Sherman E (1991) Value orientations of new-age elderly: the coming of an ageless market. J Bus Res 22(2):187194. https://doi.org/10.1016/0148-2963(91)90052-Y

52. Sirgy MJ (1982) Self-concept in consumer behavior: a critical review. Consum Res 9(3):287-300. https://doi.org/10.1086/20892 4

53. Sirgy MJ (1985) Using self-congruity and ideal congruity to predict purchase motivation. J Bus Res 13(3):195-206. https://doi. org/10.1016/0148-2963(85)90026-8

54. Sirgy MJ, Danes JE (1982) Self-image/product-image congruence models: testing selected models. In: Mitchell A (ed) NA-advances in consumer research, vol 09. Association for Consumer Research, Michigan, pp 556-561

55. Strahan EJ, Wilson AE, Cressman KE, Buote VM (2006) Comparing to perfection: how cultural norms for appearance affect social comparisons and self-image. Body Image 3:211-227. https://doi. org/10.1016/j.bodyim.2006.07.004

56. Syrdal DS, Dautenhahn K, Woods SN, Walters ML, Koay KL (2007) Looking good? Appearance preferences and robot personality inferences at zero acquaintance. In: AAAI Spring symposium: multidisciplinary collaboration for socially assistive robotics, pp 86-92

57. Thomson M, MacInnis DJ, Whan Park C (2005) The ties that bind: measuring the strength of consumers' emotional attachments to brands. J Consum Psychol 15(1):77-91. https://doi.org/10.1207/ s15327663jcp1501_10

58. Wada K, Shibata T, Saito T, Sakamoto K, Tanie K (2005) Longterm robot assisted activity at a health service facility for the aged. Proc Conf Kanto Branch 11:319-320. https://doi.org/10.1299/ jsmekanto.2005.11.319

59. Walters ML, Syrdal DS, Dautenhahn K, Te Boekhorst R, Koay KL (2008) Avoiding the uncanny valley: robot appearance, personality and consistency of behavior in an attention-seeking home scenario for a robot companion. Auton Robot 24(2):159-178. https:// doi.org/10.1007/s10514-007-9058-3

60. Weiss D, Freund AM (2012) Still young at heart: negative agerelated information motivates distancing from same-aged people. Psychol Aging 27(1):173-180. https://doi.org/10.1037/a0024819

61. Weiss D, Lang FR (2012) "They" are old but "I" feel younger: age-group dissociation as a self-protective strategy in old age. Psychol Aging 27(1):153-163. https://doi.org/10.1037/a0024887

62. White K, Argo JJ (2009) Social identity threat and consumer preferences. J Consum Psychol 19(3):313-325. https://doi. org/10.1016/j.jcps.2009.03.007

63. Wills TA (1981) Downward comparison principles in social psychology. Psychol Bull 90(2):245-271. https://doi. org/10.1037/0033-2909.90.2.245

64. Wu YH, Cristancho-Lacroix V, Fassert C, Faucounau V, de Rotrou J, Rigaud AS (2016) The attitudes and perceptions of older adults with mild cognitive impairment toward an assistive robot. J Appl Gerontol 35(1):3-17. https://doi.org/10.1177/073346481351509 2

65. Zasloff RL (1996) Measuring attachment to companion animals: a dog is not a cat is not a bird. Appl Animal Behav Sci 47(1-2):4348. https://doi.org/10.1016/0168-1591(95)01009-2

Publisher's Note Springer Nature remains neutral with regard to jurisdictional claims in published maps and institutional affiliations.

Melanie Dudek studied psychology at the Goethe University of Frankfurt am Main, Germany. She has been working as a psychologist in clinical settings and is in training to become a psychological psychotherapist. Research interests include acceptance and use of social robots, particularly in later life.

Stefanie Baisch is working as a postdoctoral researcher at the Psychological Ageing Research Unit at the University of Siegen, Germany. She studied psychology at the University of Constance, Germany, and earned her phD at the Goethe University of Frankfurt am Main, Germany. In addition, she has been working as a neuropsychologist in different clinical settings. Research interests include acceptance and use of social robots and other technologies, particularly in later life, user stereotypization, human-robot-interaction, and the use of technology for therapy and rehabilitation.

Monika Knopf is former head of the Department of Developmental Psychology at the Goethe University, Frankfurt am Main, Germany, and cofounder as well as deputy director of the Frankfurt Forum for Interdisciplinary Ageing Research (FFIA). She has studied psychology at Mannheim University where she received her diploma. Herr Ph.D. as well as her Habilitation (venia legendi for psychology) have been realized at Heidelberg University. Research interests include research on memory development across life span as well as on development of the self.

Thorsten Kolling is lecturer at the Aging Research Unit, University of Siegen, Germany. He studied psychology in Frankfurt am Main and worked at the universities of Frankfurt/Main, San Diego, Darmstadt and Kiel. His research interests include human-technology interaction from a lifespan perspective, developmental robotics, cognitive development and psychological research methods. 